\title{
Effects of Urban Matrix on Plant Diversity of Urban Remnant Mountains in Karst Area: A Case Study of Guiyang, Guizhou Province, China.
}

\author{
Na Tang \\ Guizhou University

\section{Yu Bao} \\ Guizhou University

\section{Xinyu Ma} \\ Guizhou University

\section{Guangfu Wei} \\ Guizhou University
}

Zhi-Tai Wang ( E-ztwang@gzu.edu.cn )

Guizhou University https://orcid.org/0000-0003-4602-8060

\section{Research Article}

Keywords: urban remnant hills, plant diversity, urban matrix, hilly Karst city

Posted Date: April 30th, 2021

DOI: https://doi.org/10.21203/rs.3.rs-370257/v1

License: (9) (1) This work is licensed under a Creative Commons Attribution 4.0 International License. Read Full License 


\section{Abstract}

With the rapid development of urbanization, large numbers of cone-shaped or tower-shaped isolated peaks and peak forest were surrounded by a human-dominated urban matrix in the process of urban expansion in Karst areas,forming urban remnant hills (URHs), which are important resources of indigenous plant diversity from the urban environment in these areas. Although the studies on urban plant diversity have been extensive, studies on the plant diversity of the remnant habitats, especially those based on URHs,is very weak.In this study, a total of 143 sample plots were set up on 15 hills based on the combination of slope direction and elevation.Alpha diversity was calculated at four levels, i.e.,tree,shrub,herb and whole plant.Four urban matrix characteristic indices,namely,percent total impervious surface area (PTIA), land use,vegetation coverage (VC) and fragmentation indices (FIs), were measured for each hill.Twenty scales, ranging from $100 \mathrm{~m}$ to $2000 \mathrm{~m}$ and with increasing steps of $100 \mathrm{~m}$,were used as spatial scales.Pearson correlation analysis and linear regression model were used to study the relationship between URHs plant diversity indices and urban matrix indices. The results showed the following:(1)There was a significant positive correlation between the overall plant diversity of URHs of different sizes and PTIA in the surrounding urban matrix within $1600 \mathrm{~m}$. The overall plant diversity of URHs of different scales was significantly correlated with single or multiple Land-use types. There was no significant correlation between $\mathrm{VC}$, FIand URHs overall plant diversity.(2)There was a significant linear relationship between plant diversity at all levels of different scales URHs and the four urban matrix indices. In addition to the small URHs herbaceous diversity,plant diversity at all levels of URHs was jointly affected by double or multiple factors at the $1800 \mathrm{~m}$ spatial scale. plant diversity of URHs of different scales in hilly Karst cities are extremely complex under the combined action of multiple factors and multiple scales.

\section{Introduction}

With the rapid growth of global urbanization and urban populations, many cities have been experiencing large-scale Land-use conversion (Ramalho, et al., 2014). Urban areas continue to expand to (semi-) natural areas outside their boundaries, and a large number of (semi-) natural areas are rapidly lost, split (Hayriye, et al., 2009), degraded or dispersed and embedded in a heterogeneous artificial built-up environment to form islands or island-like isolated "remnant habitats" (Fernández, et al., 2019; Han, et al., 2019). In most areas, urban expansion has destroyed (semi-) natural habitats (i.e., completely converted to the artificial environment), and few cities can retain these (semi-) natural habitats in the process of urbanization (Müller, et al., 2015). The process of habitat loss and fragmentation caused by the gradual transformation of intact habitat patches from natural land cover to impervious surfaces in urbanized areas usually has a large and negative effect on plant community species diversity(Fahrig, 2003; Kowarik \& von der Lippe., 2018). Therefore, urbanization is considered to be the main cause of urban biodiversity loss and a serious threat to urban biodiversity conservation (McKinney, 2006). Urban remnant habitats are valuable ecological resources and important potential conservation core areas of species diversity in cities (Mona, et al., 2016; Alvey, 2006; Frank, et al., 2020). They can maintain urban native biodiversity and various ecosystem processes and provide ecological well-being for urban residents (Han, et al., 2019; Guirado, et al., 2006). Due to the complexity of the urban artificial environment, research on the maintenance mechanism of species diversity in urban remnant habitats has become a popular and difficult issue in global urban ecology (Ramalho, et al., 2014) and has attracted extensive attention in the field of urban ecology (Ramalho, 2012; Schlesinger, et al., 2008). However, the scope and mechanism of the effects of urban matrix environment composition and configuration on the plant diversity of remnant habitats and at different levels are still unclear. 
The particularity of urban remnant habitats was that they are completely exposed to the heterogeneity of urban artificial built-up environments, and the matrix and the surrounding environment, in terms of both material exchange and spatial relationships, are relatively complex. In particular, the mutual influence between different landscape types and functions and changes in landscape structure and function of the influence of remnant habitat are complex and diverse(Patarkalashvil, et al., 2017; Shi, et al., 2020). Most previous studies have used the "gradient method" to explore how urbanization factors such as distance from urban centres and population density affect biodiversity in urban substrates (Kinzig, et al., 2005; Malkinson, et al., 2018). Several studies have also shown that the urban species richness had an obvious urban gradient effect(Breuste, et al., 2008; McDonnell \& Hahs, 2008). However, other scholars regarded that urban biodiversity patterns (e.g., birds and plants) were influenced by the cultural and economic status of urban residents rather than by population density, distance from urban centres, or time after disturbance (Evan, et al., 2020; Luck, et al., 2009; Hope, et al., 2003). The urbanization gradient can be used as a proxy for causal mechanisms such as disturbance state, pollutant load or predation pressure, but it does not directly affect biodiversity(Kinzig, et al., 2005). To a greater extent, it could depends on the differences in adjacent patch characteristics, landscape fragmentation, Land-use composition, and structural changes in remnant habitats with different urbanization gradients.

Some of the case studies have used indicators of urbanization as potential drivers of urban biodiversity. For example, in a study on urban plant diversity in Wuhan, China, Yan et al. (2019) showed that urban impervious surface area was an important indicator that can be used to effectively measure the impact to urban plant diversity. When the proportion of urban impervious surface area exceeds $40 \%$, urban plant diversity declineed sharply. Hayriye et al. (2009) analysed the impact of accelerated urbanization on open space protection in the Phoenix Metropolitan Area of Arizona, USA, using time series and three indicators of matrix effect, isolation and connectivity, and the results showed that increased Land-use intensity adjacent to the reserve may increase the edge effect and reduce the habitat value of the inner or core habitat area. De Souza et al. (2020) used fractional Brownian motion to study how patterns of dynamic habitat loss and fragmentation affected the level of biodiversity in an ecosystem, and the results showed that both patterns of habitat loss and environmental heterogeneity affected species distribution patterns. Ramalho et al. (2014) evaluated the impact of urban fragmentation on plant species richness in 30 Banksia remnant habitats in Perth, Australia, the results showed that the impact of rapid urban fragmentation on residual vegetation was great and complex, and these effects may take several decades to show a significant relationship. Fahrig et al. (2003) showed that multiple mechanisms may lead to positive or negative landscape scale responses to habitat fragmentation and may change with environmental change. Studies on the effects of urbanization on plant diversity in Africa, Europe and Asia have confirmed that patch size and adjacent Land-use type were important factors determining plant species composition and richness, but the direct or indirect effects of disturbance mechanisms and surrounding environmental changes may be different(Frank, et al., 2020; Guirado et al., 2006; He, et al.,2019).

Additionally, other scholars have begun to explore the potential relationship between urbanization and species diversity on a spatial scale. Fernández et al. (2019), using a multitemporal and spatial scale approach, assessed the effects of urban matrix vegetation patterns on the primary productivity of natural heritage habitats in 10 cities in Santiago (Chile), the results showed that the primary productivity of all remnant natural habitats decreased, and this decrease was spatially related to the change in vegetation cover in the surrounding urban matrix within $900 \mathrm{~m}$ and was more strongly related to the composition of the matrix. Peng et al. (2019) found that, during the urbanization process, landscape units with a radius of 600-700 $\mathrm{m}$ and different land uses had the most appropriate spatial scale range for the conservation of native plant diversity in the study on the optimal landscape 
pattern for the conservation of native plant diversity in Shunyi District, Beijing. Planchuelo et al. (2020) analysed urban matrix characteristics (e.g., impervious surface area, average floor area) within a 500-m radius around endangered plant species in Berlin, Germany, and revealed the negative impact of urbanization dynamics in Berlin (increase in the impervious surface) on the survival of endangered plant species. Although studies have revealed the potential relationships between some urbanization indicators/predictors and urban biodiversity patterns at different spatial scales, there is no unified and optimal methodological indicator to measure and evaluate the impact of urbanization development on urban biodiversity in all regions (Yan, et al., 2019). Therefore, the selection of appropriate urban matrix drivers and spatial scales could make it easier to collect data and accurately predict or reflect the effects and mechanisms of urbanization on plant diversity in remnant habitats.

The Karst area in southern China, centred on the Guizhou Plateau, is the most typical, complex and abundant Karst area in the world, as well as the largest and most concentrated ecologically fragile area (Wang, et al., 2015). Due to the special geomorphological form of solitary peaks and peak forest, in the process of urban expansion in this area, a large number of Karst hills of different scales were left as islands or island-like (hemi-) natural remnant habitats in the artificial built-up heterogeneous urban environment, formed the Karst "urban remnant hills" (URHs) habitat and the landscape mosaic of "city amomg the hills, hills in the city". The spatial form of the Karst hilly city embedded with the hills not only creates a unique city style but also forms the precious remnant ecological resources of the urban hills in the Karst hilly city(Ren, et al., 2018). Thus, this area provides an ideal research place for the ecological study of remnant habitat in an artificial urban environment.

Guiyang, located in the middle of Guizhou Province, is a typical Karst hilly city with a large number of URHs in the built-up area of the central urban area. In this study, 15 URHs in the urban built-up area of Guiyang were selected as the research object, and four indicators of urban matrix characteristics, namely PTIA, Land use, VC and FI, were adopted to explore the following questions: 1) Are there any correlations between the urban matrix characteristics and the plant diversity at different levels of the remnant hills? 2) If there is a correlation between the two, what are the main influencing factors of the characteristics of the urban matrix on the plant diversity of the remnant hills? and what is the scale effect? 3) Are the responses of plant diversity at different levels to the characteristics of the urban matrix in the remnant hills consistent?

\section{Materials And Methods}

\subsection{Study area}

This study was carried out in the central urban area of Guiyang $\left(106^{\circ} 07^{\prime}-107^{\circ} 17^{\prime} \mathrm{E}, 26^{\circ} 11^{\prime}-26^{\circ} 55^{\prime} \mathrm{N}\right)$ (Fig. 1), which is located in the hinterland of the Karst region in central Guizhou, the middle of the of the Yunnan-Guizhou Plateau, and the watershed zone between the Yangtze River and the Pearl River. The landform belongs to the Karst hilly basin area dominated by Karst solitary peaks and peak forest(Wang, et al.,2015).The zonal vegetation in the area is subtropical humid evergreen broad-leaved forests with abundant plant resources in history(Zhang, et al., 2015). In the 1980s, the total built-up area in the central urban are of Guiyang was only $22.19 \mathrm{~km}^{2}$, due to the topography of the closed Karst basin, as well as the restriction of backward economic development and a low construction level. By 2018 , the total built-up area in the central urban area of Guiyang was $368.39 \mathrm{~km} 2$, an increase of 16.6 times in 30 years. According to statistics, the permanent resident population in 2018 was 4.8819 million. The remnant hills in the built-up area are mostly scattered in the heterogeneous urban matrix environment in the form of small ,fragmented and isolated. In fact, most of the URHs at the beganing of being surrounded into built-up area still retained a large patch area, as the densification inside the city gradually approaching to the URHs, they are 
occupied and divided into smaller patches or completely devoured, this process has not yet stopped(Fig. 2).

Furthermore, there is little or no protection and management of the URHs, and the number and area of the patches are decreasing rapidly. The ecological environment is fragile and has obvious spatial heterogeneity ( $\mathrm{Mu}$, et al., 2020); thus, it is necessary to protect these special URH habitats .

\subsection{Selection and sampling design of URHs}

The URHs were divided into 3 scales: large ( $\left.\geqq 10 \mathrm{hm}^{2}\right)$, medium $\left(3-10 \mathrm{hm}^{2}\right)$ and small ( $\left.\leqq 3 \mathrm{hm}^{2}\right)$. Five URHs of each type were randomly selected, and a total of $15 \mathrm{URHs}$ were taken as research objects (Table 1). Sample plots were set according to the four-direction method (east, south, west and north), extending from the top to the foot of the each hill. Large and medium-sized URHs included 3 plots in each direction, while small URHs included 2 plots in each direction, each with an area of $30 \times 30 \mathrm{~m}^{2}$, and a total of 143 survey plots were included. Five investigation quadrats were set up in each plot according to the following criteria: tree $(10 \times 10 \mathrm{~m})$, shrub $(3 \times 3 \mathrm{~m})$ and grass $(1 \times 1$ $\mathrm{m})$. The interval between each quadrat was no less than $3-5 \mathrm{~m}$, and the quadrats were nested. A field investigation was conducted from July to October 2019 and from July to October 2020. The species name, number, height, DBH and canopy width of the trees,, the species name, height, canopy diameter and the number of trees of shrubs (including small trees), and the herbaceous species name, plant number and coverage in each quadrat were recorded. Based on the survey results, a database of plant-related information and community characteristics was constructed in Excel. Considering that the response of plants at different levels to disturbance may be different in urban continuous disturbance, therefore, four species diversity indexes (Shannon-Wiener index $(H)$, Margalef species richness index $(R)$, Simpson index $(D)$ and Pielou index $(J H)$ were calculated for the whole plant diversity and the plant diversity at different levels namely trees, shrubs and herbages(Ma,1995). Classification of native species refered to the China Plant Science Data Center (https://www.plantplus.cn/cn) and $\mathrm{FFlora}$ of Guizhou区.

Table 1

\begin{tabular}{|c|c|c|c|c|c|c|c|c|}
\hline \multicolumn{9}{|c|}{ Guiyang URHs basic information table } \\
\hline Large & & & Medium & & & Small & & \\
\hline Number & Area/hm² & District & Number & Area $/ \mathrm{hm}^{2}$ & District & Number & Area $/ \mathrm{hm}^{2}$ & District \\
\hline L1 & 10.19 & $\begin{array}{l}\text { Wudang } \\
\text { District }\end{array}$ & M1 & 4.05 & $\begin{array}{l}\text { Wudang } \\
\text { District }\end{array}$ & S1 & 1.86 & $\begin{array}{l}\text { Baiyun } \\
\text { District }\end{array}$ \\
\hline L2 & 10.52 & $\begin{array}{l}\text { Guanshanhu } \\
\text { District }\end{array}$ & M2 & 4.36 & $\begin{array}{l}\text { Yunan } \\
\text { District }\end{array}$ & S2 & 2.57 & $\begin{array}{l}\text { Wudang } \\
\text { District }\end{array}$ \\
\hline L3 & 11.23 & $\begin{array}{l}\text { Yunan } \\
\text { District }\end{array}$ & M3 & 5.59 & $\begin{array}{l}\text { Nanming } \\
\text { District }\end{array}$ & s3 & 1.85 & $\begin{array}{l}\text { Nanming } \\
\text { District }\end{array}$ \\
\hline L4 & 14.01 & $\begin{array}{l}\text { Nanming } \\
\text { District }\end{array}$ & M4 & 4.99 & $\begin{array}{l}\text { Huaxi } \\
\text { District }\end{array}$ & S4 & 2.89 & $\begin{array}{l}\text { Huaxi } \\
\text { District }\end{array}$ \\
\hline L5 & 17.40 & $\begin{array}{l}\text { Huaxi } \\
\text { District }\end{array}$ & M5 & 3.83 & $\begin{array}{l}\text { Wudang } \\
\text { District }\end{array}$ & S5 & 1.46 & $\begin{array}{l}\text { Baiyun } \\
\text { District }\end{array}$ \\
\hline
\end{tabular}

\subsection{Classification of landscape types}

The 2018 Pleiades high-resolution satellite image ( $0.5 \mathrm{~m}$ spatial resolution) of the study area was obtained as the basic data source for buffer analysis and urban matrix analysis. According to the Classification of Land Use Status 
(GB/T21010-2017) and based on the ArcGIS software platform, landscape types were divided into two categories: construction land and non-construction land. Construction land was further divided into residential land (R), public management and public service land (A), commercial service facilities land (B), industrial land (M), logistics and storage land $(W)$, transportation facilities land (S), public facilities land $(U)$ and green land (G). The nonconstruction land was further divided into cultivated land (E21), woodland (E22), grassland (E31), water area (E1), natural mountain (EG) and unused land (E32). The spatial attribute database was established for the research area.

\subsection{Urban matrix characteristic indexes}

In this study, four urban matrix characteristics (PTIA, Land use, $V C$, and $F$ ) were selected to explain the potential effects of urban matrix composition and structural complexity on URH plant community species diversity(Yan, et al., 2019; Hayriye, et al., 2009; Wu, 2007). The calculation was as follows:

$\mathrm{PTIA}=\left(\mathrm{BZT} \mathrm{PTIA}_{\mathrm{A}} / B A\right) \times 100 \%$

In the formula, the percent total impervious area of the buffer zone (BZT PTIA $)$ refers to the sum of the land area of 7 types: $\mathrm{R}, \mathrm{A}, \mathrm{B}, \mathrm{M}, \mathrm{W}, \mathrm{S}$, and $\mathrm{U}$. Buffer area $(B A)$ refers to the total area of all land types in the buffer zone.

$V C=\left(B Z T_{V C} / B A\right) \times 100 \%$

In the formula, the total vegetation cover of the buffer zone (BZT $v c$ ) refers to the sum of 6 land uses: G, E21, E22, E31, E1, and EG. Buffer area $(B A)$ refers to the total area of all land types in the buffer zone.

$F I=P_{i} / S_{i}$

where $P i$ is the number of patches of landscape $i$, and $S i$ is the total area of landscape $i$.

\subsection{Urban matrix characteristic indexes}

Since multiple (potential) ecological processes affected by the urban matrix landscape structure occur at different spatial scales, their scope of influence and relative importance may vary with the size of the landscape(Smith, et al., 2011). In this study area, in order to quantify the potential effects and spatial scale effects of the above matrix indicators on URHs plant diversity at all levels, based on Arcgis10.2 Multiple Ring Buffer tools, the foot lines of 15 sample hills were used as baselines, 20 annular buffers were generated at $100 \mathrm{~m}$ step length of, with a maximum buffer width of $2000 \mathrm{~m}$. The buffer zone was superimposed with the landscape type attributes of the study area established in Sect. 2.3 to calculate the urban matrix characteristics of the buffer zones.

The landscape surrounding each sample hill was assessed in terms of the landscape metrics given in Sect. 2.4, and they were calculated for each buffer zone in each of the 15 URHs.

\subsection{Urban matrix characteristic indexes}

Pearson correlation analysis was used to detect the significant relationships between the four diversity indices and the four urban matrix indices, and between the diversity indices and the urban matrix indices, and a multiple linear regression model was established. The correlation and significance of urban matrix characteristic indices on the plant diversity at different levels in the URHs were compared to try to find the most suitable urban matrix characteristic factors and influence scale range to explain URHs plant diversity in Karst hilly cities. Data analysis was performed using Microsoft Excel and SPSS 19.0 software. 


\section{Results}

\subsection{Species composition, structure and diversity of URH plant communities}

In total, 581 plant species belonging to 456 genera and 150 families were recorded in this survey. Among them, 347 species belonging to 295 genera and 112 families were recorded in large URHs, and 220 native and 127 alien species were recorded. A total of 333 species belonging to 279 genera, 105 families, 226 native species and 107 alien species were recorded in medium-scale URHs. A total of 383 species belonging to 308 genera, 128 families, 238 native species and 145 alien species were recorded in small-scale URHs. There was no significant difference in the average number of families, genera, species, native species and alien species and in the mean species number of trees, vines and herbs,but there was a significant difference in the shrub layer among the three scales of URHs, and decreasing with the increase in scale as follows: small URHs (35) > medium URHs (32) >large URHs (25) (Fig. 3).

There were significant differences in all levels plant diversity among the three scale types of URHs, showing that the overall plant diversity of different scale URHs was medium URHs > small URHs > large URHs, the plant diversity of trees and herbs of different scale URHs were large URHs > medium URHs > small URHs, and the shrub plant diversity of different scale URHs showed a trend of small URHs > medium URHs > large URHs (Fig. 4).

\subsection{Effects of urban matrix characteristics on plant diversity in URHs}

\subsubsection{Influence of PTIA on plant diversity indices at different levels in the URHs}

There were significant spatial scale effects on the effect of buffer zone PTIA to overall plant diversity indices of all scales URHs, The width of buffer zone of best-fitting relationships between of PTIA and overall plant diversity indices was $1400 \mathrm{~m}, 1600 \mathrm{~m}$ and $100 \mathrm{~m}$ for large, medium and small URHs respectively, and the overall plant diversity indices showed significant positive correlations with PTIA (Fig. 5).

The diversity indices of trees were negatively correlated with PTIA in the $1500 \mathrm{~m}$ buffer zone of large URHs, $900 \mathrm{~m}$ buffer zone of medium URHs respectivelty,but was positively correlated with PTIA in $600 \mathrm{~m}$ buffer zone of smll URHs. There were significantly positive correlation between the diversity indices of shrub and PTIA in the $100 \mathrm{~m}$ buffer zone of large URHs and in the $1700 \mathrm{~m}$ buffer zone of medium URHs respectively,but not correlation with PTIA of buffer zone of small URHs. The diversity indices of herbs was negatively correlated with PTIA in $100 \mathrm{~m}$ buffer zone of medium URHs, but had no significant correlation with PTIA of buffer zone of large and small URHs (Fig. 5).

\subsubsection{Impact of Land-use type on overall plant diversity and plant diversity indices at all levels in URHs}

The overall plant diversity of large URHs was positively correlated with residential land R. The overall plant diversity of medium URHs was negatively correlated with Land-use types A, G, E21, and E1. There was a significant negative correlation between the overall plant diversity of small URHs and the E32 Land-use types (Fig. 6).

The responses of plant diversity indices of different levels of URHs in different scales to Land-use types were different. Large URHs tree diversity indices were negatively correlated with R, E1, and E31; shrub diversity indices 
was negatively correlated with E1; and herbs diversity indices were positively correlated with $\mathrm{G}$ and $\mathrm{E} 1$ and negatively correlated with E21 and E22. The tree diversity indices of medium URHs were negatively correlated with $\mathrm{M}$, and shrub diversity indices were positively correlated with E22 and negatively correlated with A and E1, but herbs diversity was not significantly correlated with Land-use type. There were a significant positive correlation between the diversity indices of tree and shrub and E32 in small URHs and a significant negative correlation between herb diversity indices and EG and E32 (Fig. 8).

\subsubsection{Effects of VC on the species diversity of URH plant communities}

The results showed that there was no significant correlation between overall plant diversity indices in all URHs and $V C$ in any scale buffer (Fig. 7).

There were significant differences in the spatial response of plant diversity indices at different levels to buffer $V C$ in URHs of different sizes. Among them, the herbs diversity indices of large URHs were significantly negatively correlated with $V C$ in the $100 \mathrm{~m}$ buffer zone. There was a significant positive correlation between the diversity indices of shrubs of medium URH and $V C$ in the range of $300 \mathrm{~m}$. There was a significant negative correlation between the diversity indices tree and shrub of small URHs and $V C$ at $700 \mathrm{~m}$ and $1800 \mathrm{~m}$, respectively. There was no significant correlation between the diversity indices of trees and shrubs of large URH and $V C$ in any scale, as well as trees and herbs of medium URH and herbs or small URH (Fig. 7).

\subsubsection{Impact of urban substrate FI on overall plant diversity and plant diversity at different levels in URHs}

Figure 8 showed that there was no significant correlation between buffer Fland overall plant diversity indices in large- and medium-sized URHs. However, there was a significant negative correlation between buffer $\mathrm{Fl}$ and the overall plant diversity of small URHs within $200 \mathrm{~m}$.

Figure 8 shows the relationship between plant diversity at different levels of URHs and F/in buffer zone. Result showed that: there was no consistency in the spatial scale response of plant diversity at different levels of URHs to Fl of buffer zone, there was a significant positive correlation between the shrubs diversity of large URH and F/ within $400 \mathrm{~m}$ buffer zone, a significant positive correlation between tree diversity and $\mathrm{Fl}$ at $1600 \mathrm{~m}$ in medium URHs and a significant negative correlation between shrub diversity and $F /$ at $200 \mathrm{~m}$, a significantly negative correlation between the diversity indices of trees and shrubs of URHs and F/in the range of $100 \mathrm{~m}$.

\subsubsection{Multiple linear regression analysis of urban matrix characteristic indexes and URHs for overall plant diversity} and plant diversity at different levels

According to the regression simulation results (Fig. 9), PTIA, Land use, Fland VC were the important driving factors for explaining and predicting the effects of urban matrix on plant species diversity of URHs. The overall plant diversity of URHs was significant linear relationship with PTIA and Land use but no significant correlation with FI, $V C$. However, there was a significant linear relationships between plant diversity at all levels of different scales URHs and the four indices. The diversity of trees, shrubs and herbaceous plants in large and medium-sized URHs and the diversity of trees and shrubs in small URHs were both influenced by the superposition and coupling of double or multiple driving factors. Herbaceous diversity of only small URHs was affected by a single driver of Land use. 


\section{Discussion}

\subsection{Species composition and diversity of URH plant communities}

Previous studies have shown that patch size was a key determinant of species diversity but may differ due to direct or indirect impacts of human activities on urban environments(Guirado, et al., 2006). The results of this study showed that although patch area was one of the factors that explained the plant diversity at different levels URHs, but the relationship was weak. There was no significant difference in the plant community composition and structure of URHs in different scale. Medium URHs could maintain higher overall plant diversity, large URHs could maintain high tree and herbaceous diversity, while small URHs showed higher shrub diversity. The urban artificial environment is characterized by continuous and repeated interference by human factors (Zarzycki, et al., 2002). In the human-dominated urban matrix environment, the maintenance of species diversity and ecological processes in the remnant habitat are largely determined by the type, degree, and frequency of interference of human activity. In particular, the strong human disturbance caused by the transformation of the landscape basement greatly changed the relative influence of patch size and even topographic factors on the species diversity of the remnant habitats (Matlack, 1993). Therefore, considering patterns of plant diversity in patch characteristics alone is not enough to explain the potential effects of other disturbances.

\subsection{PTIA and plant diversity at various levels of URH}

The PTIA is an important indicator to measure the urban environment and urbanization degree. Some scholars have confirmed that PTIA had a negative impact on the plant diversity in urban area (Yan, et al., 2019; Peng, et al., 2019). A study by Planchuelo et al. (2020) on the impact of urbanization dynamics on endangered plant species in Berlin also showed that $36 \%$ of endangered plant species were locally extinct within 10 years with increase of PTIA. In contrast, the results of this study showed that PTIA had a positive impact on the overall plant diversity of all scale URHs in the range of 100-1600 m. In addition, the effects of PTIA on plant diversity at different levels of URH of different sizes were significantly different in the range of 100-1700m (for example, tree diversity of large and medium-sized URHs was negatively correlated with PTIA, while shrub diversity was positively correlated). The complicating factors that explain this result may be follows: (1) URHs were mostly surrounded by transportation networks and residential areas, which are more conducive to plant propagation or pollen spread to some extent. (2) There is a phenomenon of park utilization in URHs of different scales, and the artificial introduction and planting of garden ornamental plants (though most of them are probably alien species) provide a good growth environment and conditions. (3) The phenomenon of reclamation and cultivation by the surrounding residents exists in most of the URHs. To provide good illumination and growth conditions for crops, not only were the upper trees and shrubs cut down, but herbicide was also used to remove the herbaceous plants, which increased the probability of the introduction or invasion of alien species. These factors suggest that rational planning management may be beneficial to maintaining a high level of plant diversity (Muratet, et al., 2008). However, excessive human disturbance would change the disturbance mechanism between the habitat environment and adjacent substrates, leading to differences in the responses of plant diversity at different levels to the environment.

\subsection{Land use and URM overall plant diversity and plant diversity at different levels}

The urban matrix is a complex mosaic composed of different landscape units. Matrix type is an important component of the landscape background, especially in human-dominated urban landscape environments (Vandermeer \& Carvajal, 2001; Kupfer, et al., 2006). The landscape structure formed by different Land-use types and 
their configurations can significantly shape and regulate the composition and diversity of plant communities (Walz, 2015). The results of this study showed that Land-use composition in $1600 \mathrm{~m}$ width buffer zone significantly affected the plant diversity at all levels in URHs, but the correlations were significantly different. Similar to the results of Sect. 3.2, residential and industrial Land-use types may have positive impacts on plant diversity, while non-construction Land-use types such as woodland, cultivated land, and grassland may have negative impacts; moreover, they may be influenced by multiple Land-use types at the same time. This result aslo proved that the composition and structure of land cover and land use on a small scale space are highly complex and dynamic (Luck \& Wu, 2002). The complex urban matrix mosaic was formed by the superposition and interaction between the Land-use types of Karst hilly cities and the topography of Karst basin. The high connectivity of impervious surface land uses might lead to the superposition effect of a single land use type on URHS plant community, or lead to different land use between the mechanism of action of offset each other, which might lead to differences in the results. Additionally, different Land-use types have different effects on the integrity of remnant habitat and the change degree of habitat conditions and have different effects on plant communities. Moreover, differences in adaptability and anti-disturbance ability of different plant community structures and species characteristics to urbanization disturbances might lead to different results.

\subsection{VC and URH overall plant diversity and plant diversity at all levels}

Of course, not all urban matrix factors have positive or negative effects on URH plant community species diversity. The results of this study showed that $V C$ had no significant correlation with the overall plant diversity of URHs of different areas within the buffer radius of $2000 \mathrm{~m}$. Further analysis of the potential effects of buffer VC on plant diversity at all levels of different URH showed that: there were significant differences in the response of plant diversity at different URHs levels to $V C$ within the buffer range of 100-1800 m. In some areas, the composition and structure of matrix vegetation cover can play an effective role in regulating the negative impacts of fragmentation on biodiversity in remnant habitats (Ruffell, et al., 2017; Brunbjerg, et al., 2018). In contrast, some studies have shown that there is a quadratic relationship between urban matrix vegetation cover and neighbourhood age, but there is not a significant positive correlation until approximately 45 years (Grove, et al., 2006; Troy, et al., 2007). This result suggests that improving substrate quality by increasing vegetation cover in a short period may not be a useful strategy to maintain or protect the species diversity and ecosystem integrity of URH plant communities.

\subsection{FI and plant diversity at different levels of URHs}

Although the impacts of landscape fragmentation on the plant communities in remnant habitats are diverse and complex, it doesn't necessarily to have a direct impact (Ramalho, et al., 2014). In this study, we found that buffer FI had no significant effect on the plant diversity of large and medium URHs. However, there was a negative effect between buffer $\mathrm{Fl}$ and overall plant diversity in small URHs at $200 \mathrm{~m}$ buffer. It might be the time-delay effects of fragmentation on plant diversity in the remnant habitats. Generally, remnant habitats with larger areas, better landscape connectivity, and long-lived species, might need a longer time to response to fragmentation, while those with smaller areas might have a quick response in shouter time to fragmentation(Planchuelo, et al., 2020). The rapid development of urbanization in Guiyang began almost 30 years ago, so it is not clear to what extent and spatial scale the overall plant diversity of large and medium-sized URHs would be affected by fragmentation. These answers could be revealed only after long-term observation and recording. Further analysis of the effects of fragmentation on the plant diversity at different levels of URHs showed that fragmentation in the range of $1600 \mathrm{~m}$ was correlated with the trees and shrubs diversity of URHs. However, there was no significant correlation between buffer fragmentation and herbs plant diversity of URHs. These results indicated that different remnant habitats and 
different plant community structures had different responses to dynamic changes in the urban matrix. At present, Guiyang city is in a stage of rapid urban expansion and internal densification. Long-term and continuous direct human activities have caused vegetation degradation in this area for a long time, and there are serious ecological problems, such as soil erosion, soil reaction, and rock exposure (Shen, et al., 2020).Under the synergistic effect of internal habitat conditions and external urban matrix changes, plant diversity at all levels might easily changes with disturbance, even if the patch area is relatively large.

\subsection{Spatial scale dependence of overall plant diversity and plant diversity at different levels in URHs}

Since multiple (potential) ecological processes affected by the urban matrix landscape structure occur at different spatial scales, their scope of influence and relative importance might vary with the size of the landscape (Smith, et al., 2011). Chase et al. (2018) regarded that biodiversity was multidimensional and scale dependent, and the scale effect of one influencing factor does not well predict the scale effect of another factor. Both natural factors and human drivers could affect or significantly change biodiversity at different scales in multiple ways. The plant diversity of URHs was influenced by the superposition and coupling of double or multiple urban matrix indices at the $1600 \mathrm{~m}$ scale. However, the influence range and relative importance of different urban matrix indices on plant diversity of URHs were significantly different with changes in the substrate environment and disturbance mechanism. In addition, the diversity of different level plant had different responses to urban spatial forms at different spatial scales. Some responded to environmental changes at a small scale (100-400 m), while the others responded to urban spatial forms at a larger scale (1600-1800 m). These results further supported the conclusion of Sadler et al. (2006) that "different taxa/species respond to urban spatial forms at different spatial scales", and also indicated that the overall plant diversity of URHs, the influencing factors and the spatial scale range of plant diversity at all levels were complex and diverse.

According to the results of this study and the theory of "extinction debt" and previous studies, it is known that the response of remnant habitat plant communities to urbanization migth be significantly negative correlation after decades or longer.The results of this study confirmed the previous hypothesis that the response of plants at different levels to urban matrix disturbance was different when the URHs were continuously disturbed by human beings. Therefore, future studies should consider the impact of dynamic changes of landscape patterns in urban matrix (historical evolution of land use) on plant diversity in remnant habitats. Therefore, future studies should consider the impact of dynamic changes of landscape patterns in urban matrix (historical evolution of land use) on plant diversity of remnant habitats, and refine the effects of intensity and frequency of human activity interference (engineering construction, engineering facilities, slope hardening and greening, cultivation, cemeteries, etc.) within remnant habitats on plant communities and different levels of plants. It is suggested that in the process of urban development and construction in the future, multiple influencing factors and mechanisms should be considered for different remnant habitats in the time dimension and different spatial scales.

\section{Conclusions}

The ecological processes and community structure changes of URHs in the artificial built-up environment of Karst hilly cities are more complex due to the combined effects of multiple factors on different scales. The complexity of the influencing factors increase the challenge of URHs protection and management.Based on this study, it is concluded that (1) There was a significant positive correlation between the overall plant diversity of URHs of different sizes and PTIA in the surrounding urban matrix within $1600 \mathrm{~m}$. The overall plant diversity of URHs of

Page 11/23 
different scales was significantly correlated with single or multiple Land-use types, but the impact effects were significantly different. There was no significant correlation between VC, Fland URHs overall plant diversity. (2) There was a significant linear relationship between plant diversity at all levels of different scales URHs and the four urban matrix indices. In addition, the herbaceous plant diversity of small size remnant hills showed a significant linear relationship with only Land use, but in other URHs, the plant diversity at all levels was affected by double or multiple factors at the range of $1800 \mathrm{~m}$. Plant species diversity and community structure of URHs of different scales in hilly Karst cities are extremely complex and diverse under the combined action of multiple factors and multiple scales. Therefore, in the process of urban green space ecology system planning, urban spatial planning and urban renewal, the multiple influence factors and their mechanism to different scales URHs at different scales should be considered to provide a scientific reference and to help protect remnant habitat plant community species diversity.

\section{Declarations}

\section{Ethics approval and consent to participate}

All authors have read and approve this version of the article, and due care has been taken to ensure the integrity of the work. No part of this paper has published or submitted elsewhere.

\section{Consent for publication}

All authors have read and consented to the article being submitted or published in the journal.

\section{Availability of data and materials}

The acquisition, processing and writing of data and materials in this paper were conducted in accordance with the author's guidelines and did not pose any threat to personal or national security.

\section{Conflicts of Interest / Competing Interests}

The authors have no conflicts of interest to declare that are relevant to the content of this article.

\section{Author contributions}

All authors contributed to the study conception and design. Material preparation, data collection and analysis were performed by Na Tang, Yu Bao,Xinyu Ma and Guangfu Wei. Writing-review and editing by Zhitai Wang. The first draft of the manuscript was written by Na Tang and all authors commented on previous versions of the manuscript. All authors read and approved the final manuscript.

\section{Funding and Acknowledgement}

This work was supported by the National Natural Science Foundation of China (NSFC) (32060367); Guizhou Provincial Science and Technology Foundation ([2020]1Z011); Guizhou Province Science and Technology Support Plan Project ([2021]458).

\section{Declaration of interests}


$\nabla$ The authors declare that they have no known competing financial interests or personal relationships that could have appeared to influence the work reported in this paper.

\The authors declare the following financial interests/personal relationships which may be considered as potential competing interests:

All authors have read and approve this version of the article, and due care has been taken to ensure the integrity of the work. No part of this paper has published or submitted elsewhere. No conflict of interest exits in the submission of this manuscript.

\section{References}

1. Ramalho CE, Laliberté E, Poot $P$, Hobbs RJ Complex effects of fragmentation on remnant woodland plant communities of a rapidly urbanizing biodiversity hotspot. Ecology. 2014, 95,9,2466-2478

2. Hayriye E, Edward AC, Joseph E Effects of Increasing Urbanization on the Ecological Integrity of Open Space Preserves. Environmental Management. 2009, 43,5

3. Fernández IC, Wu JG, Simonetti JA (2019) The urban matrix matters: quantifying the effects of surrounding urban vegetation on natural habitat remnants in Santiago de Chile. Landscape Urban Planning 187:181-190

4. Han HQ, Liu Y, Cai GP, Bai YM, Ma SL, Chen SY, Luo RY Characteristics of Gradient Change of Value of Mountain Ecosystem Services with the Rapid Urbanization in Urban Area. Research of Soil and Water Conservation.2020,27,05, 295-303

5. Müller A, Bøcher PK, Svenning JC (2015) Where are the wilder parts of anthropogenic landscapes? A mapping case study for Denmark. Landscape Urban Planning 144:90-102

6. Fahrig (2003) L.Effects of habitat fragmentation on biodiversity. Annu Rev Ecol Evol Syst 34:487-515

7. Kowarik I, von der Lippe M. Plant population success across urban ecosystems: A framework to inform biodiversity conservation in cities. Journal of Applied Ecology.2018,55,2354-2361

8. McKinney ML Urbanization as a major cause of biotic homogenization. Biological Conservation.2006, 127, 247-260

9. Mona Lisa Veríssimo Silva de Araújo.; Bernard E Green remnants are hotspots for bat activity in a large Brazilian urban area. Urban Ecosystems.2016,19,1, 287-296

10. Alvey AA (2006) Promoting and preserving biodiversity in the urban forest. Urban Forestry Urban Greening 5(4):195-201

11. Frank BC, Kafumbata D, Chanyenga T, Chiotha, S.Urban tree species composition and diversity in Zomba city, Malawi: Does land use type matter? Urban Forestry \& Urban Greening.2020,54

12. Guirado M, Pino J, Rodà F Understorey plant species richness and composition in metropolitan forest archipelagos: effects of forest size, adjacent land use and distance to the edge. Global Ecology and Biogeography.2006,15,1,50-62

13. Ramalho CE, Hobbs RJ (2012) Time for a change: dynamic urban ecology. Trends Ecol Evol 27(3):179-188

14. Schlesinger MD, Manley PN, Holyoak (2008) M.Distinguishing stressors acting on land bird communities in an urbanizing environment. Ecology 89:2302-2314

15. Patarkalashvili TK (2017) Urban forests and green spaces of Tbilisi and ecological problems of the city. Annals of Agrarian Science 15(2):187-191

Page 13/23 
16. Shi NF, Liu, SL;An, Y, Sun YX, Dong SK, Wu (2020) X.Changes of landscape fragmentation and connectivity with urbanization: a case study of Kunming city. Acta Ecolojica Sinica 40(10):3303-3314.(in chinese with english abstract)

17. Kinzig AP, Warren P, Martin C, Hope D, Katti, M.The effects of human socioeconomic status and cultural characteristics on urban patterns of biodiversity. Ecology and Society.2005,10,1, 23

18. Malkinson D, Kopel D, Lea (2018) W.From rural-urban gradients to patch-matrix frameworks: Plant diversity patterns in urban landscapes. Landscape Urban Planning 169:260-268

19. Breuste J, Niemelä J, Snep RPH (2008) Applying landscape ecological principles in urban environments. Landscape Ecol 23:1139-1142

20. McDonnell MJ, Hahs AK (2008) The use of gradient analysis studies in advancing our understanding of the ecology of urbanizing landscapes: current status and future directions. Landscape Ecol 23(10,):1143-1155

21. Evan RK, Paige SW, John AZ, Myla FJA, Sarel C, Mark AG, Charles HN, Richelle WUrban socioeconomic inequality and biodiversity often converge, but not always: A global meta-analysis. Landscape and Urban Planning.2020,198

22. Luck GW, Smallbone LT, O’Brien R Socio-Economics and Vegetation Change in Urban Ecosystems: Patterns in Space and Time. Ecosystems. 2009,12,4

23. Hope D, Gries C, Zhu WX, Fagan WF, Redman CL, Grimm NB, Nelson AL, Martin C, Kinzig ASocioeconomics (2003) Drive Urban Plant Diversity. Proc Natl Acad Sci USA 100:15,8788-8792

24. Yan ZG, Teng MJ, He W, Liu AQ, Li YR, Wang PC (2019) Impervious surface area is a key predictor for urban plant diversity in a city undergone rapid urbanization. Sci Total Environ 650:335-342

25. De Souza CAM, Daza SLC, de Lima Filho JA, Campos PRA, de Oliveira VM.Effect of dynamic fragmentation on biodiversity in a heterogeneous environment. Physics Letters A.2020,384,22

26. He RX, Yang F, Yan PB, Liang HYEffects of Urban Land Use on Plant Diversity: A Case Study of Haikou City,China. Journal of Chinese Urban Forestry.2019,17,04,12-17.(in chinese with english abstract)

27. Peng Y, Mi K, Wang HT, Liu ZW, Lin YY, Sang WG, Cui QT (2019) Most suitable landscape patterns to preserve indigenous plant diversity affected by increasing urbanization: A case study of Shunyi District of Beijing, China. Urban Forestry Urban Greening 38:33-41

28. Planchuelo G, Kowarik I, von der Lippe M. Plant traits, biotopes and urbanization dynamics explain the survival of endangered urban plant populations. Journal of Applied Ecology.2020,57,8,1581-1592

29. Wang SJ, Zhang XB, Bai XY An outline of karst geomorphology zoning in the karst areas of southern china. Mountain Research.2015,33,6,641-648.(in chinese with english abstract)

30. Ren M, Bao Y, He LY Analysis of landscape pattern of urban greenland in karst mountainous region -a case study of Anshuncity. Journal of Mountain Agriculture and Biology.2018,37,6, 54-62.(in chinese with english abstract)

31. Zhang JY, Dai MH, Wang LC, Su WC, Cao LG (2015) Plant selection and their ecological adaptation for rocky desertification control in karst region inthe southwest of China. Earth Environment 43:03,269-278.(in chinese with english abstract)

32. Mu HJ, Cui WG, Lu X Spatial and temporal pattern of inpervious surface in typical mountainous cities of karst. Journal of University of Jinan(Science and Technology).2021,35,01,34-40 + 61.(in chinese with english abstract) 
33. Ma KP, Huang JH, Yu SL, Chen LZ (1995) Plant community diversity in dongling mountain,Beijing, China: âه区. species richness, evenness and species diversities. Acta Ecolojica Sinica 15(3):268-277. (in chinese with english abstract)

34. Wu JG Landscape ecology - pattern, process, scale, and hierarchy(2nd edition). Higher Education Press.2007,37-40.(in chinese with english abstract)

35. Smith AC, Fahrig L, Francis CM Landscape size affects the relative importance of habitat amount, habitat fragmentation, and matrix quality on forest birds. Ecography.2011,34, 103-113

36. Zarzycki K, Trzcińska-Tacik H, Różański W, Szeląg Z, Wołek J, Korzeniak UEcological indicator values of vascular plants of vascular plants of Poland.Biodiversity of Poland, W. Szafer Institute of Botany, PAN: Kraków, Poland.2002

37. Matlack GR (1993) Sociological edge effects-spatial-distribution of human impact in suburban forest management. Environ Manage 17:829-835

38. Muratet A, Porcher E, Devictor V, Arnal G, Moret J, Wright S; Machon, N. Evaluation of floristic diversity in urban areas as a basis for habitat management. Applied Vegetation Science.2018,11,4,451-460

39. Vandermeer J, Carvajal R (2001) Metapopulation dynamics and the quality of the matrix. Am Nat 158:3,211220

40. Kupfer JA, Malanson GP, Franklin SB (2006) Not seeing the ocean for the islands: the mediating inflfluence of matrix-based processes on forest fragmentation effects. Global EcolBiogeogr 15:8-20

41. Walz (2015) U.Indicators to monitor the structural diversity of landscapes. Ecol Model 295:88-106

42. Luck M, Wu, J (2002) A gradient analysis of urban landscape pattern: a case study from the Phoenix metropolitan region, Arizona, USA. Landscape Ecol 17(4):327-339

43. Ruffell J, Clout MN, Didham RK (2017) The matrix matters, but how should we manage it? Estimating the amount of high-quality matrix required to maintain biodiversity in fragmented landscapes. Ecography 40:1,171-178

44. Brunbjerg AK, Hale JD, Bates AJ, Fowler RE, Rosenfeld EJ, Sadler JP (2018) Can patterns of urban biodiversity be predicted using simple measures of green infrastructure? Urban Forestry Urban Greening 32:143-153

45. Grove JM, Troy AR, O’Neil-Dunne JPM, Burch WR, Cadenasso ML, Pickett STA Characterization of Households and its Implications for the Vegetation of Urban Ecosystems. Ecosystems.2006, 9,4, 578-597

46. Troy AR, Grove JM, O’Neil-Dunne JP, Pickett ST, Cadenasso ML Predicting Opportunities for Greening and Patterns of Vegetation on Private Urban Lands.Environmental Management.2007,40,3,394-412

47. Shen YZ, Zeng MX, Lin DG, Peng HJ, Zhu LD, Li FQ, Yu YH, Wang NJ. Impacts of human factors on net primary productivity of vegetation in Guizhou province from 2000 to 2014.Carsologica Sinica.2020,39,01,62-70.(in chinese with english abstract)

48. Chase JM, McGill BJ, McGlinn DJ, May F, Blowes SA, Xiao X, Knight TM, Purschke O, Gotelli NJ (2018) Embracing scale-dependence to achieve a deeper understanding of biodiversity and its change across communities. Ecol Lett 21:11

49. Sadler JP, Small EC, Fiszpan H, Telfer MG, Niemela Jlnvestigating environmental variation and landscape characteristics of an urban-rural gradient using woodland carabid assemblages. Journal of

Biogeography.2006,33,6,1126-1138

\section{Tables}

Page 15/23 


\begin{tabular}{|c|c|c|c|c|c|c|c|c|}
\hline Large & & & Medium & & & Small & & \\
\hline Number & Area/hm² & District & Number & Area/hm² & District & Number & Area/hm² & District \\
\hline L1 & 10.19 & $\begin{array}{l}\text { Wudang } \\
\text { District }\end{array}$ & M1 & 4.05 & $\begin{array}{l}\text { Wudang } \\
\text { District }\end{array}$ & $\mathrm{S} 1$ & 1.86 & $\begin{array}{l}\text { Baiyun } \\
\text { District }\end{array}$ \\
\hline L2 & 10.52 & $\begin{array}{l}\text { Guanshanhu } \\
\text { District }\end{array}$ & M2 & 4.36 & $\begin{array}{l}\text { Yunan } \\
\text { District }\end{array}$ & S2 & 2.57 & $\begin{array}{l}\text { Wudang } \\
\text { District }\end{array}$ \\
\hline L3 & 11.23 & $\begin{array}{l}\text { Yunan } \\
\text { District }\end{array}$ & M3 & 5.59 & $\begin{array}{l}\text { Nanming } \\
\text { District }\end{array}$ & S3 & 1.85 & $\begin{array}{l}\text { Nanming } \\
\text { District }\end{array}$ \\
\hline L4 & 14.01 & $\begin{array}{l}\text { Nanming } \\
\text { District }\end{array}$ & M4 & 4.99 & $\begin{array}{l}\text { Huaxi } \\
\text { District }\end{array}$ & S4 & 2.89 & $\begin{array}{l}\text { Huaxi } \\
\text { District }\end{array}$ \\
\hline L5 & 17.40 & $\begin{array}{l}\text { Huaxi } \\
\text { District }\end{array}$ & M5 & 3.83 & $\begin{array}{l}\text { Wudang } \\
\text { District }\end{array}$ & S5 & 1.46 & $\begin{array}{l}\text { Baiyun } \\
\text { District }\end{array}$ \\
\hline
\end{tabular}

\section{Figures}

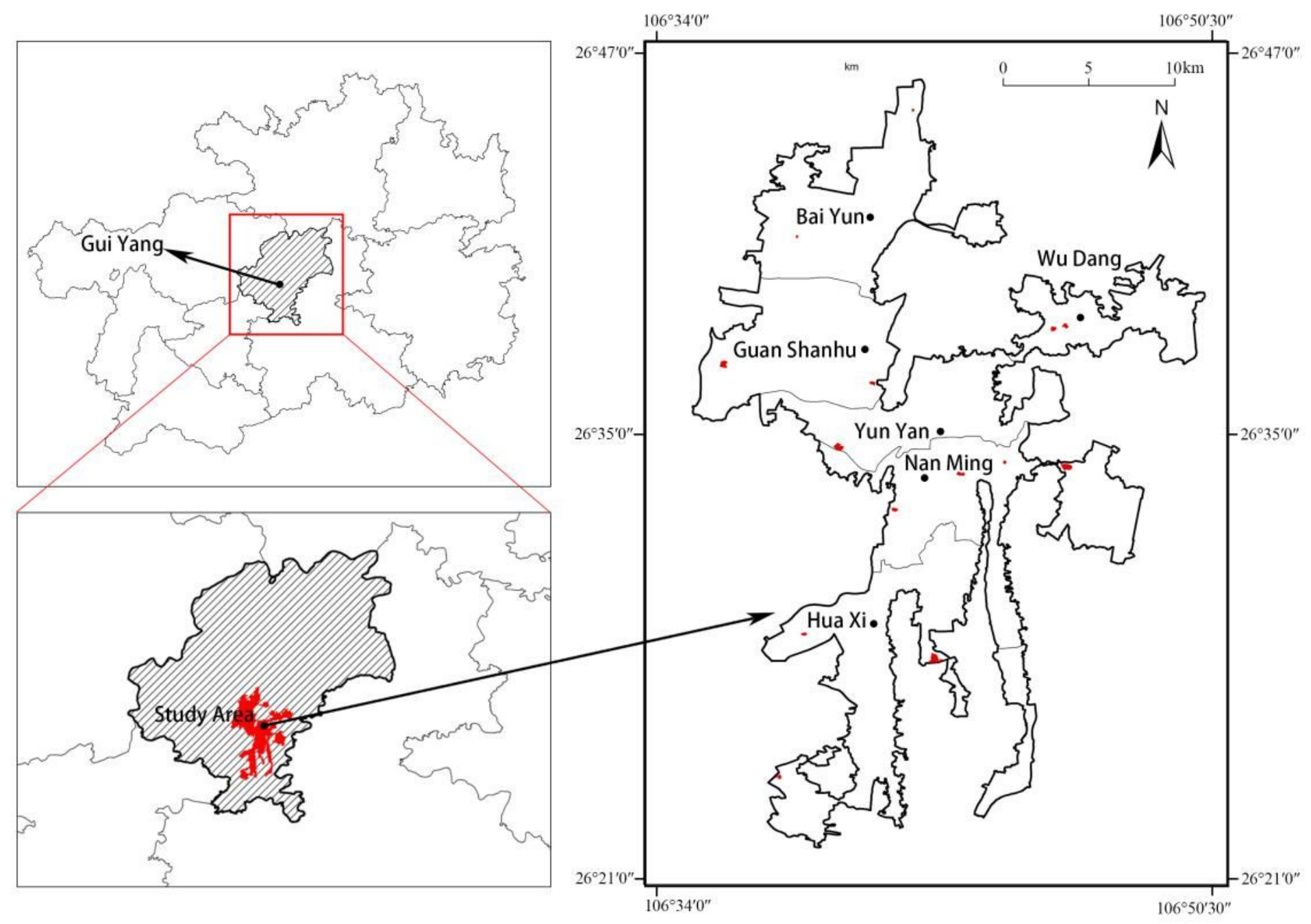

Figure 1 
Area of study Note: The designations employed and the presentation of the material on this map do not imply the expression of any opinion whatsoever on the part of Research Square concerning the legal status of any country, territory, city or area or of its authorities, or concerning the delimitation of its frontiers or boundaries. This map has been provided by the authors.
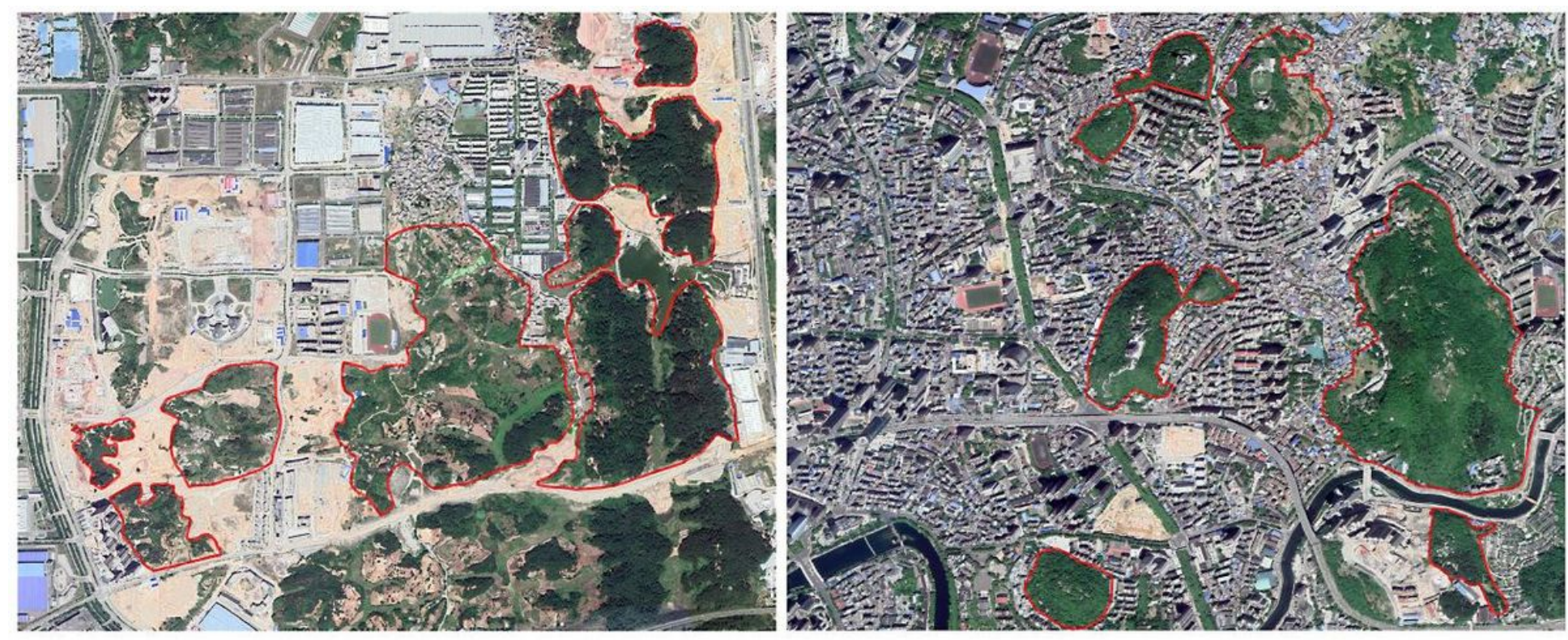

Figure 2

URH being eroded and destroyed by urbanization (left) and completely surrounded by impervious urban matrix (right) Note: The designations employed and the presentation of the material on this map do not imply the expression of any opinion whatsoever on the part of Research Square concerning the legal status of any country, territory, city or area or of its authorities, or concerning the delimitation of its frontiers or boundaries. This map has been provided by the authors.

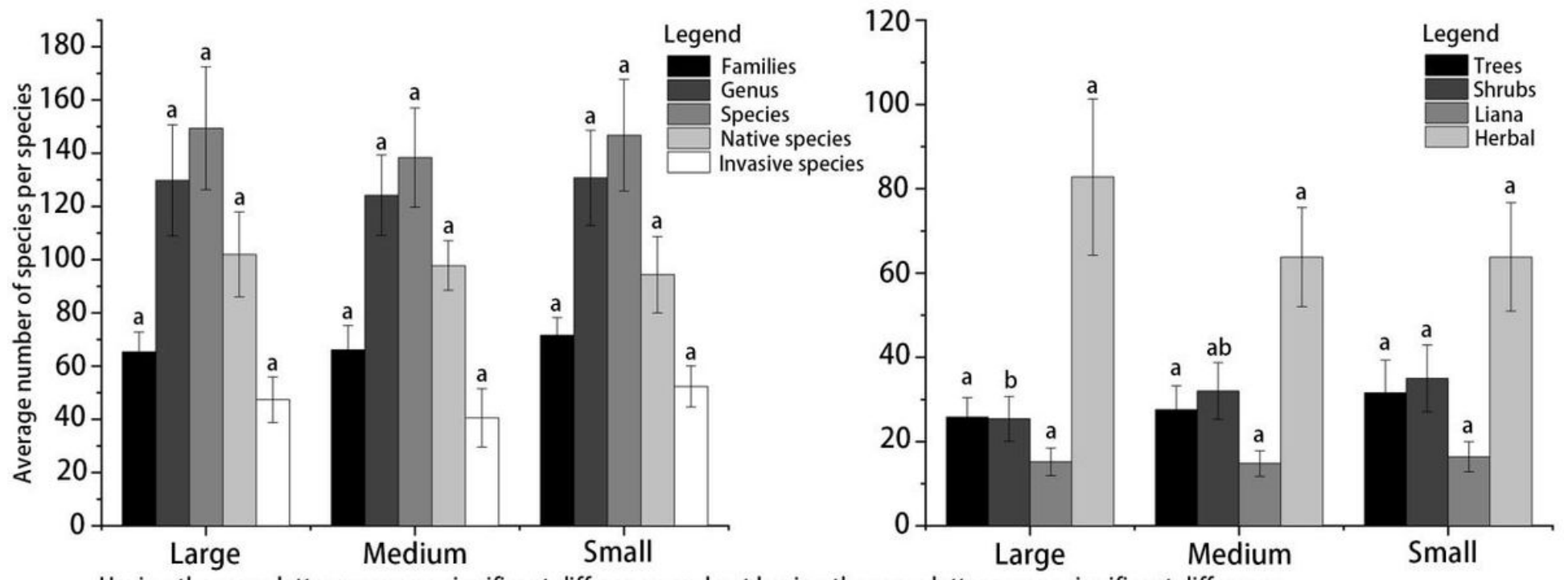

Having the same letter means no significant difference, and not having the same letter means significant difference

\section{Figure 3}

Analysis of the species composition of the URH plant community in the built-up area of Guiyang city 

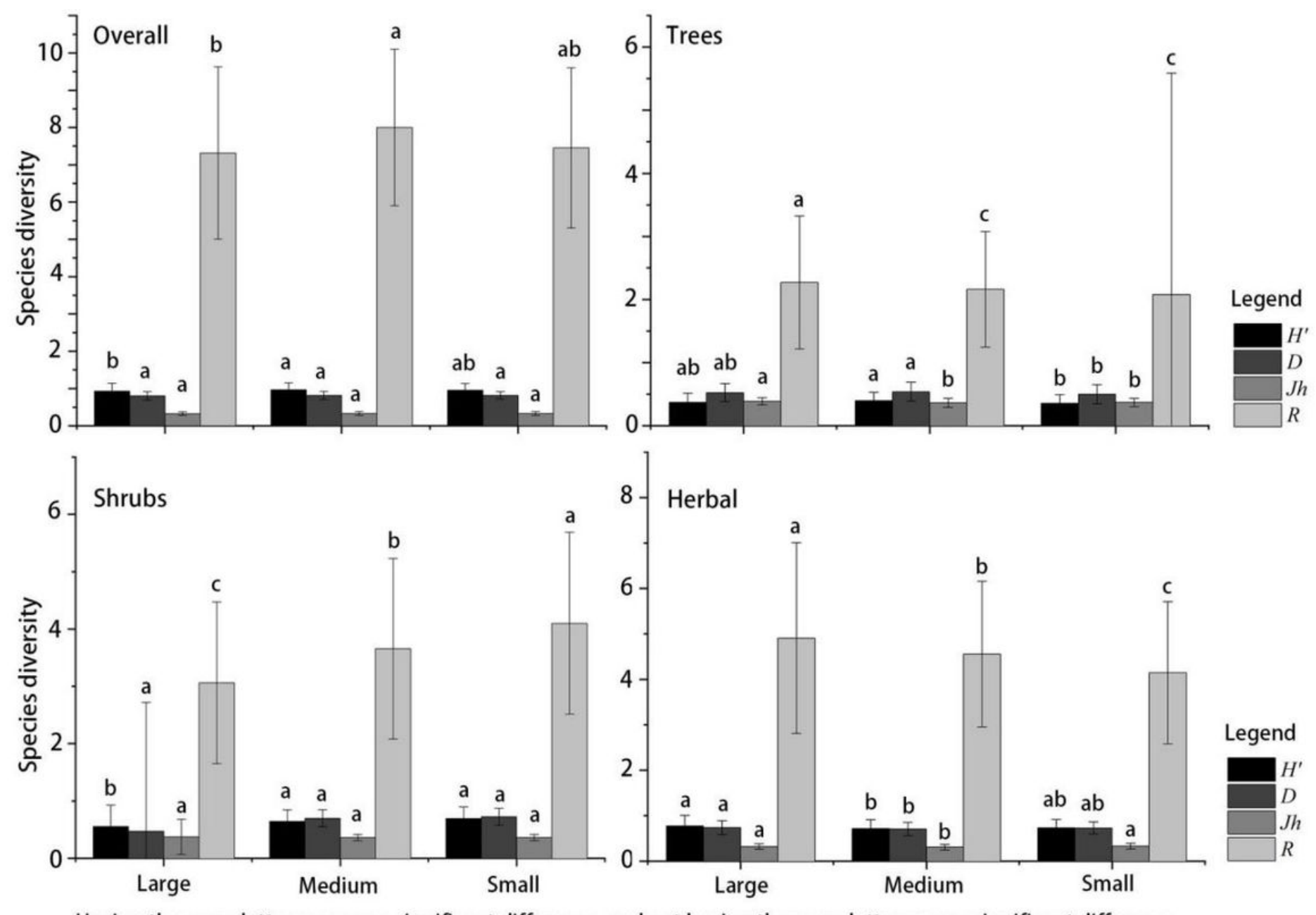

Having the same letter means no significant difference, and not having the same letter means significant difference

Figure 4

Analysis of the species diversity characteristics of the URH plant community in the built-up area of Guiyang city 

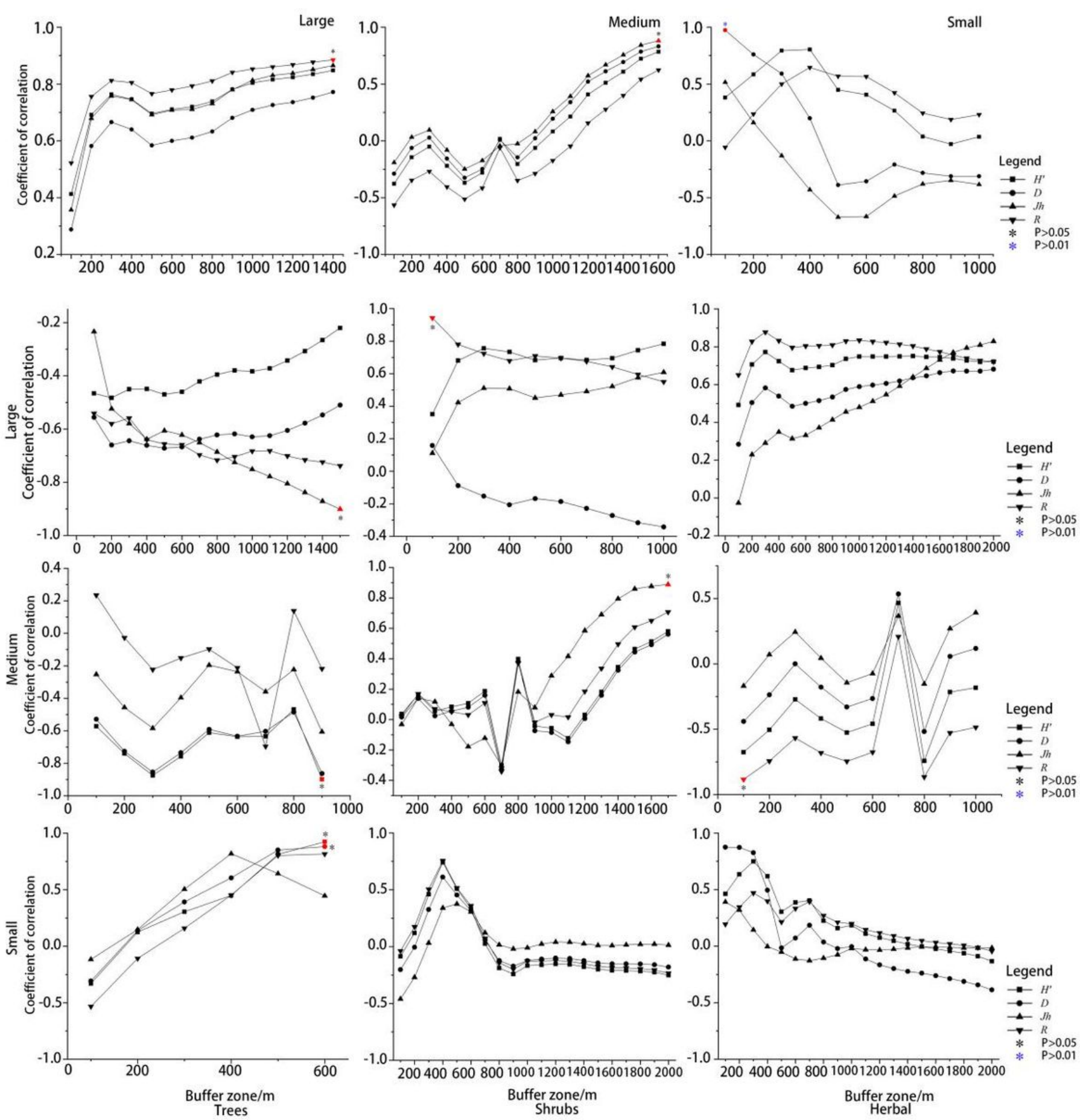

Figure 5

Relationship between plant diversity of URHs and PTIA in buffer zone 

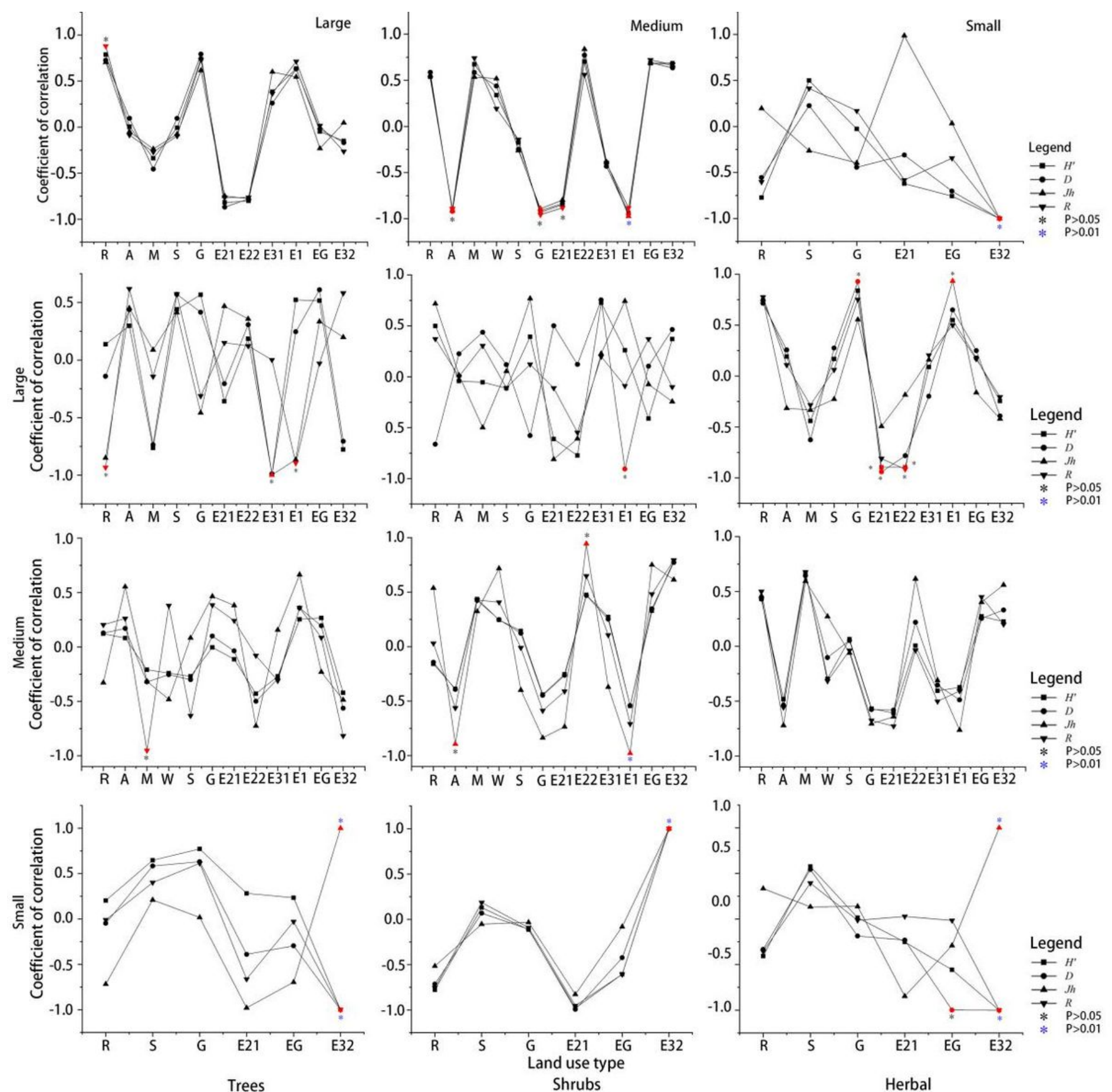

Figure 6

Relationship between plant diversity of URHs and Land use in buffer zone 

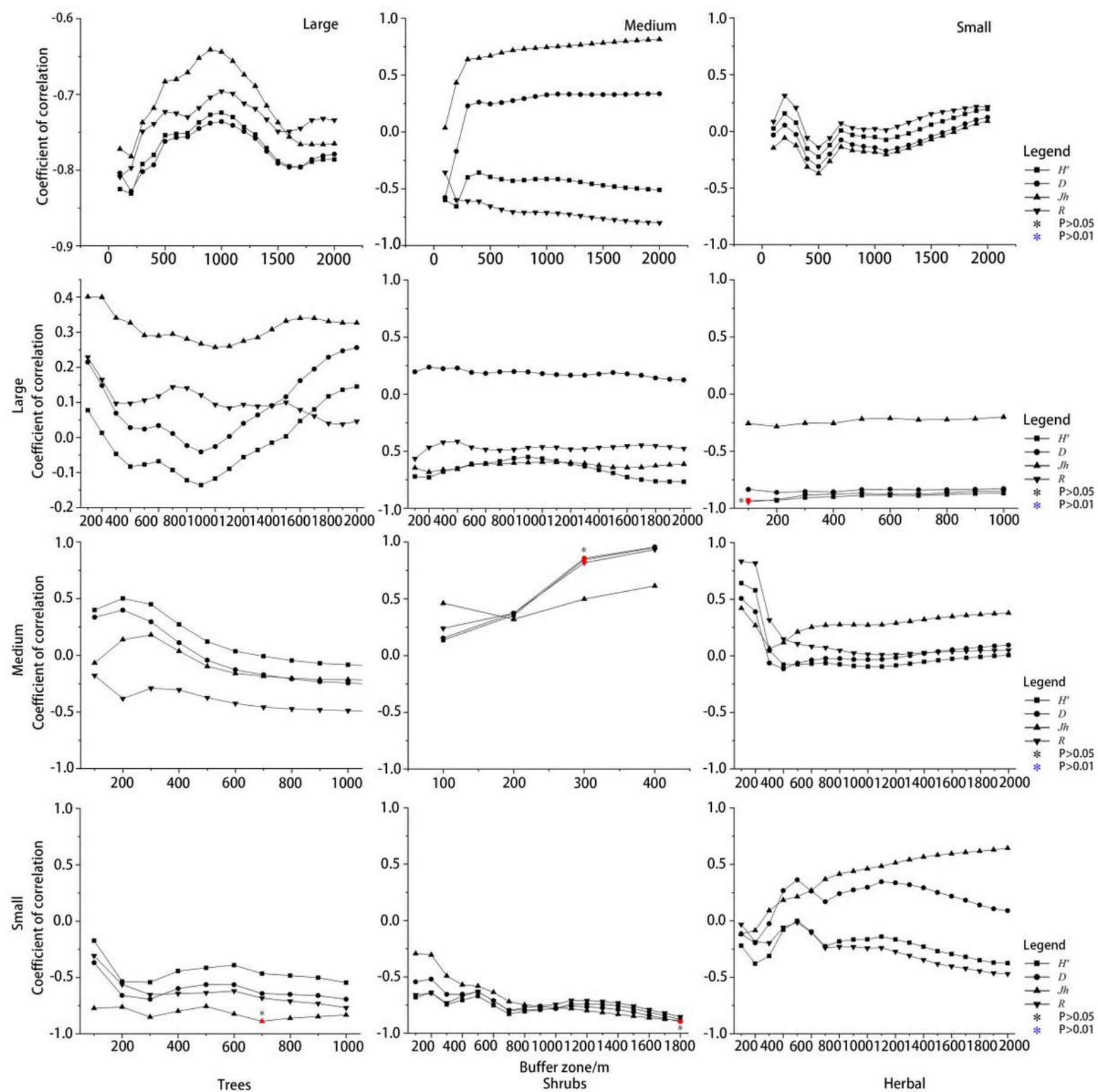

Figure 7

Correlation analysis between land use in the buffer zone and plant community structure and species diversity in URHs 

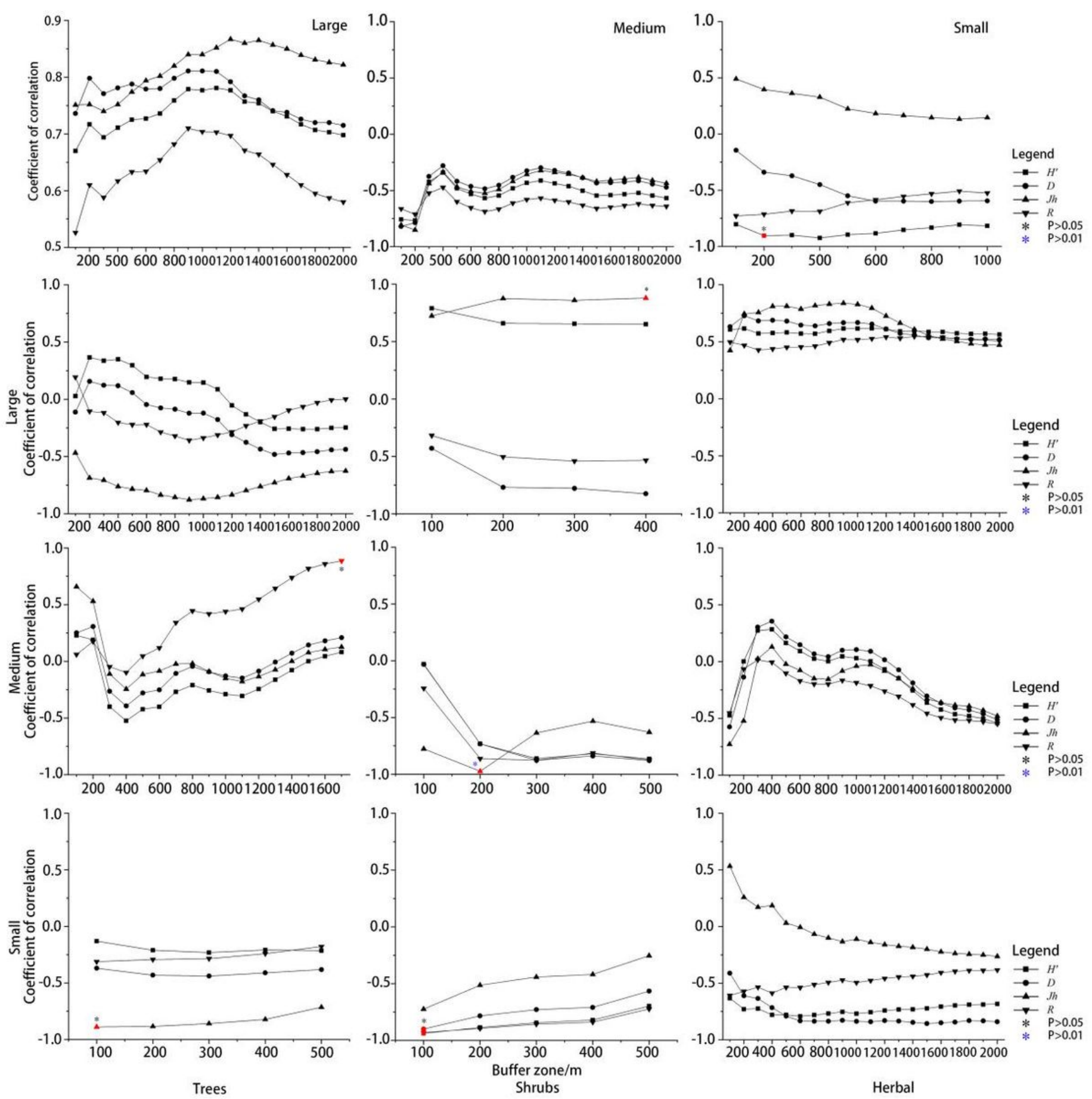

Figure 8

Relationship between plant diversity of URHs and FI in buffer zone 

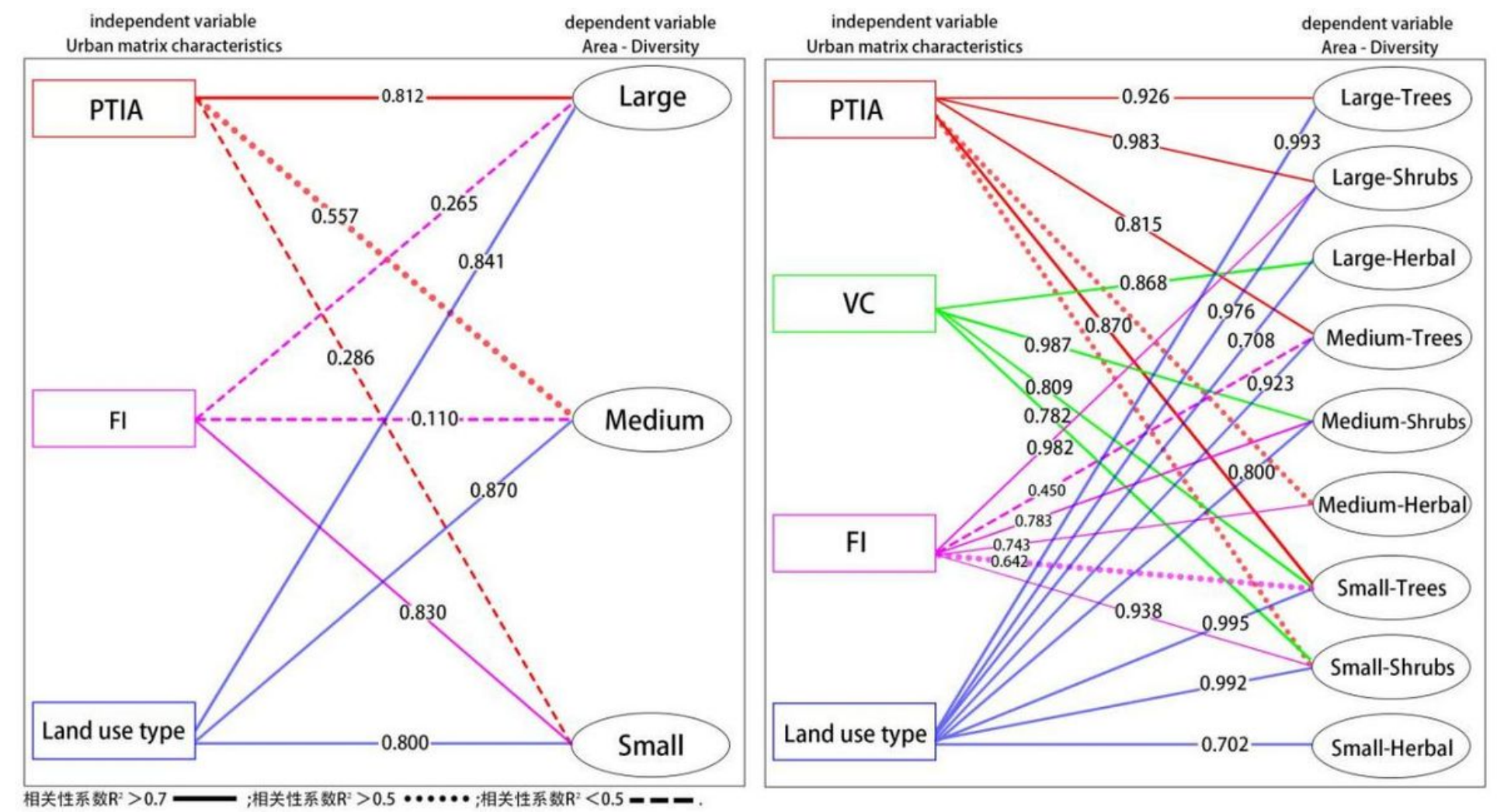

\section{Figure 9}

Linear regression simulation analysis 